\title{
Price adjustment in the London housing market
}

\author{
Rob Webb ${ }^{1}$, Duncan Watson ${ }^{2}$ and Steve Cook $^{3,4}$
}

\begin{abstract}
Recent research into the dynamic adjustment of prices within the London housing market is extended via the application of a novel two-step procedure. Combining the non-parametric analysis of the ranking distributions of the levels and changes in house prices with the application of a cross-sectional convergence technique, the analysis results in the detection of a three-tier system in which highly significant convergence clubs are identified within borough-level data. These findings contrast with both the divergence apparent when considering all boroughs and the failure of previous research to identify convergent groupings. The novelty of the empirical methods is supplemented by a discussion of various theoretical factors such as gentrification, displaced demand, immigration, foreign investment and criminal activity in relation to the findings obtained.
\end{abstract}

Webb R, Watson D \& Cook S, Price adjustment in the London housing market, Urban Studies, 58(1), pp. 113-130. Copyright $\odot$ The Authors 2019. Reprinted by permission of SAGE Publications. Reuse is restricted to non-commercial and no derivative uses. DOI: $10.1177 / 0042098019878349$

${ }^{1}$ University of Nottingham Business School.

2 School of Economics, University of East Anglia.

3 Department of Economics, Bay Campus, Swansea University, Swansea SA1 8EN. S.cook@swan.ac.uk.

${ }^{4}$ Corresponding author. 


\section{Introduction}

Recent decades have witnessed the emergence of a vast literature examining the properties and nature of housing markets. This wealth of research is unsurprising in light of the variety of factors illustrating the importance of housing, including: the substantial contribution of housing to personal wealth; the role of housing in the macroeconomy; the interaction between housing and economic fundamentals; and the increased importance of housing, relative to the stock market, to consumption decisions (Goetzmann 1993; Brueckner 1997; Holly and Jones 1997; Gallin 2006; Goodhart and Hoffman 2007; Bayer et al. 2010; Costello et al. 2011; Case et al. 2013; Han 2013). Considering the UK, despite important early empirical analyses at a national level (see, inter alia, Nellis and Longbottom 1981; Hendry 1984), arguably the most prominent theme of this research involves examination of the dynamic adjustment of, and interrelationships between, regional house price series. At the heart of this work is the analysis of the ripple effect hypothesis under which changes in house prices are observed firstly in London before being witnessed in other regions. From early studies such as Guissani and Hadjimatheou (1991), MacDonald and Taylor (1993), Alexander and Barrow (1994) through to Hudson et al. (2018), this hypothesis has received extensive attention, with a variety of methods employed to determine the presence and nature of this diffusion mechanism. However, an interesting development of this regional analysis is provided by the work of Abbott and De Vita (2012), hereafter referred as ADV, in which dynamic adjustment has been considered at yet more disaggregated level via a borough-level examination of the London market. ${ }^{1}$ In addition to its analysis of an unquestionably important market given its size, value ${ }^{2}$

\footnotetext{
1 The analysis of ADV considers the 32 boroughs of London plus the City of London. However, while the City of London is not a borough, the term borough-level analysis is used in reference to the work of ADV for simplicity.

2 The value of the London housing is well recognised. In 2015 the combined value of the housing stock in Northern Ireland, Scotland and Wales amounted to under $38 \%$ of the value of the London housing stock (see http://www.savills.co.uk/blog/article/198459/residential-property/uk-housing-value-tops-6-trillion.aspx).
} 
and position at the heart of the ripple effect, the work of ADV provides a highly quantitative supplement to the more discursive analysis of the London market provided by Hamnett (2009a,b) and Slater (2009).

It is the analysis of ADV and its inference of limited convergence within the London market which provide the motivation for the present study. To explore convergence within the London market, ADV employed the pairwise unit root based approach of Pesaran (2007). While providing useful information on the dynamic adjustment of prices, this prompts two issues for further consideration. First, as the analysis of stochastic convergence using unit root testing requires longer spans of data, its suitability for the present analysis can be questioned as observations on prices at the level of disaggregation considered are available from 1995 only. Second, the analysis of ADV does not directly focus upon the identification of groupings of regions. Instead, all possible pairings of boroughs are examined and although various collections of these pairs are considered as specific groupings within the overall market, these subgroupings are taken from the GLAEconomics (2014) report rather than arising as a result of their creation via detailed analysis. That is, the groupings are imposed exogenously rather than endogenously determined via the information available. In recognition of these issues, the present study reconsiders the properties of London house prices via an alternative and novel empirical method which exploits the cross-sectional dimension of the borough-level data to support the identification of potential convergence clubs within the market. Consequently, the present research develops the analysis of ADV and the subsequent work of Holmes et al. (2018) which also applies the pairwise unit root testing to borough-level data without the objective of defining convergence clubs.

To achieve its aims, this paper proceeds as follows. Initially, the analysis examines potential convergence in the form $\sigma$-convergence (Friedman 1992; Quah 1993) across all 32 London 
boroughs via examination of the temporal properties of the cross sectional coefficient of variation of house prices. This form of convergence is explored to avoid the above data-related issues associated with unit root testing of stochastic convergence and criticisms associated with examination of $\beta$-convergence via Barro-Baumol regressions (Barro, 1991; Baumol 1986). This analysis results in the detection of house price divergence rather than convergence. This is consistent with the findings of ADV in which limited evidence of stochastic convergence is apparent. However, the current analysis is then developed to consider the ranking distributions of prices and changes in house prices. Drawing upon the long established non-parametric methods of Friedman (1937) and Nemenyi (1963), commonalities in rankings are considered to identify potential convergence clubs which are then examined using the above $\sigma$ convergence technique. The methods are employed in preference to other techniques as they relate directly to ranking distributions where interesting dynamic adjustment exists. For this reason, the current approach is utilised rather than the alternative $\log t$ test of Phillips and Sul (2007) which has proved popular in the convergence literature. This novel two-step procedure proves successful in the present context as the analysis of ranking distributions detects substantial movement in the distributions of prices and their changes which can be exploited to form groupings of boroughs to act as potential convergence clubs. The subsequent analysis of these clubs results in detection of substantial convergence between these clearly defined clusters. Interestingly, the identified clubs do not reflect the sub-markets proposed by GLAEconomics (2014) and subsequently considered by ADV. Instead, the novel results obtained demonstrate the existence of a three-tier clustering of boroughs within the London market lying between 'elite' pairing of boroughs and a single trailing borough at the tail of the distribution. Interestingly, the three groupings detected indicate the importance of an Inner/Outer London distinction with the top convergence club surrounding the elite pairing of Kensington \& Chelsea and the City of Westminster, and the lowest club occupying the outer 
regions of Greater London. The middle grouping in the three system occupies a position to the North West of central London. In all cases, the contiguous nature of groupings is apparent. However, the crucial difference between the clubs identified in the present study and those considered previously in the literature is simply that they provide evidence of overwhelmingly significant convergence.

The analysis undertaken is deliberately data-driven with the intention of extracting information available in the borough-level series to improve understanding of the dynamic adjustment of prices within the London market and the levels at which commonalities and differences exist. This subsequently allows two issues to be addressed. First, the insights obtained can be related to alternative theoretical proposals which have emerged in relation to the London market such as displaced demand (Hamnett, 2009a), (super-) gentrification (Hamnett, 2009b; Slater 2009), criminal activity (Gibbons, 2004) and immigration and foreign investment (Badarina and Ramadorai 2018). Second, the re-examination of convergence within the London market following the alternative methods and objectives present in the studies of ADV and Holmes et al. (2018) addresses the ever-increasing calls for the replication of empirical research emerging in a variety of disciplines by providing, in the terminology of Clemens (2017), a re-analysis of this research.

\section{Reviewing the literature}

The analysis of the evolution of regional house prices and their interrelationships has generated a large empirical literature. At the heart of this research is the examination of the notion of a ripple effect whereby price changes are observed firstly in a leading region before spreading to others. While this hypothesis has been considered for a range of economies, it is arguably the 
UK which has received the greatest attention, with the proposed transmission of changes in house prices from London to the rest of the UK examined. ${ }^{3}$ To explore the existence and nature of this mechanism, a range of alternative techniques have been employed including causality testing, unit root and cointegration analysis, Kalman filtering, principal component analysis, directional forecasting methods and probability-based convergence techniques to examine whether London 'leads' other regions and, if so, how house prices eventually converge across regions (see, inter alia, Holmans 1990; Guissani and Hadjimatheou 1991; MacDonald and Taylor, 1993; Alexander and Barrow 1994; Drake 1995; Ashworth and Parker 1997; Meen 1999; Petersen et al. 2002; Cook 2005a, 2005b, 2012; Holmes 2007; Holman and Grimes 2008; Cook and Watson 2015; Hudson et al., 2018). In recent research, this analysis has been extended by ADV to consider an increased level of disaggregation via a borough-level examination of the London housing market. This extension of the literature to consider a more detailed analysis of the London market is an unquestionably important development. Beyond the value and importance of the London market to the macroeconomy, ADV note also that the examination of its underlying properties is warranted as a result of its role at the heart of the ripple effect and the limited number of studies exploring housing at an intra-regional level. Consequently, there is a clear motivation for studying the nature of price adjustment within the London market. ${ }^{4}$

The focus of ADV concerned the extent of convergence between house prices across London boroughs. Using the pairwise unit root approach of Pesaran (2007), ADV examined the

\footnotetext{
3 Given the focus of the present analysis upon the London housing market, the discussion of the ripple effect hypothesis is in relation to the UK market. However, analysis of the ripple effect has an international dimension including examination of, inter alia, Australia, China, South Africa and the USA (see, inter alia, Le and Liu, 2013; Zhang et al. 2017; Balcilar et al. 2013; Payne 2012 respectively).

${ }^{4}$ In addition to examination of convergence, the London housing market has received attention in works such as Nygaard and Meen (2013) and Cook and Watson (2017) where the longer term evolution of both aggregate London prices and the cyclical properties of borough-level prices, respectively, have been examined. However, neither study considers the issue of convergence within this market.
} 
possibility that while borough-level house prices might diverge over the short term, they converge to an underlying equilibrium over the longer run. This analysis of stochastic convergence was performed in two stages. In the first stage, an analysis of the full set of boroughs was conducted. This was found to provide little evidence of convergence as application of the testing procedure under 6 different testing options resulted the detection of convergence in only $11.93 \%$ to $27.27 \%$ of the pairings of boroughs examined. ${ }^{5}$ The second stage of the analysis involved the examination of 11 subsets of boroughs, or clubs, identified by GLAEconomics (2004) on the basis of their common characteristics. Again, the results provided limited evidence of convergence aside from a 'Central' club involving just four 'boroughs' (City of London, Camden, Kensington \& Chelsea; City of Westminster). ${ }^{6}$ However, even for this group the results were not overwhelmingly supportive of convergence as two of the six sets of results detected convergence in only half of the pairings considered. Beyond these findings for the Central Club, other clubs were found to offer very little evidence of significance. For example, only $5.13 \%$ to $12.82 \%$ of the pairings within the 'Crowded House' club demonstrated convergence depending on the variant of the unit root testing employed. In summary, the analysis found varying but limited evidence of convergence both across the whole market and within alternative clubs. However, the analysis undertaken can be reconsidered as the unit root based method adopted by ADV requires a long span, or calendar period, of data to be employed to examine stochastic convergence. ${ }^{7}$ Consequently the suitability of this approach can be questioned for the short span of data (1995-2009) examined

\footnotetext{
5 Rather than employ a single unit root test, ADV considered 3 tests with 2 approaches for determining the lag orders of each, thus leading to 6 applications of unit root testing for each pair of series considered. The detection of convergence was found to vary for across these 6 different specifications.

${ }^{6}$ Again, while a local authority and included in the analysis of ADV, the City of London is not a borough.

${ }^{7}$ The importance of a long span of data rather than a large number of observations per se for the effective application of unit root tests has been long recognised in the literature following the work of Shiller and Perron (1985).
} 
by ADV. The subsequent research of Holmes et al. (2018) develops the analysis of the London market via consideration of further disaggregation by property type (detached, semi-detached and terraced houses along with flats). Using both Pesaran's (2007) approach to pairwise analysis of stochastic convergence and probit analysis, this research produces some interesting findings including the increased convergence apparent for more expensive (detached, semidetached properties) and the impact of travel options, crime and schooling. However, like ADV, this analysis does not seek to identify convergence clubs and the consideration of convergence is again based upon the use of unit root testing and hence is subject to the concerns raised previously concerning the time series dimension of the data considered.

In recognition of the issues discussed in relation to previous research, the present study explores the convergence and distribution of borough-level house prices using an alternative novel approach which exploits the cross-sectional dimension of the data under examination. This analysis takes the form of a two-step procedure involving the analysis of the rankingsdistributions of house prices $(p)$ and changes in house prices $(\Delta p)$ across boroughs followed by examination of the presence of $\sigma$-convergence. In essence, the first step of this procedure elicits information on the commonalities and differences in the adjustment of prices across boroughs which allows the identification of potential convergence clubs. The second step of this procedure then considers whether significant convergence is present within these clubs using a method which is not subject to the concerns of associated with unit root based methods and exploits information in the cross section nature of the data set. The results obtained provide evidence of three-tier system of highly significant convergence clubs which contrasts to finding of divergence when considering the London market as a whole.

In the process of providing a more detailed examination of the distribution of, and relationships between, house prices within the London market, the current analysis supports a large and 
evolving 'replication' literature questioning the robustness of empirical findings and the encouraging the re-examination of previous studies. While perhaps most closely associated with the 'replication crisis' in psychology (see Open Science Collaboration, 2015), calls for replication have been witnessed in numerous disciplines (see, inter alia, Winfree, 2010; Frank and Saxe, 2012; Makel and Plucker, 2014; McNeeley and Warner, 2015; Chang et al., 2017; Sukhtankar, 2017). The prominence of this issue is reflected also in journal policies towards replication (Hoffler, 2017) with the emergence of associated data repositories and special editions dedicated to this topic (for example, Energy Economics and International Review of Law and Economics). Employing the 'replication' terminology of Clemens (2017), the present study provides a re-analysis of $\mathrm{ADV}$ as a result of the application of alternative empirical methods over an extended sample period. Importantly, this re-analysis proves informative by extending the findings of earlier research.

\section{Data and Initial Analysis of Convergence}

The data employed in the present analysis are annual observations on median house prices for the 32 boroughs of Greater London over the period 1995 to 2016. In addition to covering a longer period than that considered by ADV, the data employed differ also in terms of their frequency. While data at a quarterly frequency as examined by ADV are available, these are calculated in a rolling year format with the values presented providing information on house prices over a year to the relevant quarter. As a consequence of this moving average feature with events in a particular period included in a number of observations, annual data are instead 
employed in the present study. The house price data for all boroughs are presented in Figures One and Two. ${ }^{8}$

\section{[ Figures One and Two about here]}

Examination of these figures suggests a certain rigidity in house prices with, for example, house prices in Kensington and Chelsea, City of Westminster, Camden, Hammersmith and Fulham, Islington, Richmond upon Thames and Wandsworth consistently high relative to other boroughs. However, series being consistently high (or low) relative to others obviously does not preclude the existence of convergence as it may be that the distribution is narrowing. To explore potential $\sigma$-convergence, the cross-sectional coefficient of variation $\left(C V_{t}\right)$ is calculated as $C V_{t}=\sigma_{t} / \bar{p}_{t}$, where $\sigma_{t}$ and $\bar{p}_{t}$ denote the standard deviation and mean of house prices respectively across the 32 boroughs in period $t$. A plot of $C V_{t}$ through time is provided in Figure Three where $C V_{t}$ is scaled to take the value 100 in the initial period (1995) to ease interpretation. Aside from a narrowing of the distribution of house prices in the early years of the $21^{\text {st }}$ century and six (of twenty two) years having a value of $C V_{t}$ below its initial value, the overall conclusion is that house prices have diverged, with the spread as measured by the coefficient of variation being $21 \%$ greater at the end of the sample than at the start. However, as noted above, the absence of convergence when considering all boroughs does not prevent the existence of convergence clubs. This possibility is explored in the following section using a method built upon the consideration of ranking distributions.

\footnotetext{
8 The boroughs and the abbreviations employed in graphical presentations are as follows: Barking \& Dagenham (BRK); Barnet (BAR); Bexley (BEX), Brent (BRN); Bromley (BRM); Camden (CAM); Croydon (CRY); Ealing (EAL); Enfield (ENF); Greenwich (GRE); Hackney (HCK); Hammersmith \& Fulham (HAM); Haringey (HRG); Harrow (HAR); Havering (HAV); Hillingdon (HIL); Hounslow (HND); Islington (ISL); Kensington \& Chelsea (KEN); Kingston upon Thames (KNG); Lambeth (LAM); Lewisham (LEW); Merton (MRT); Newham (NEW); Redbridge (RED); Richmond upon Thames (RCH); Southwark (STH); Sutton (SUT); Tower Hamlets (TWR); Waltham Forest (WLT); Wandsworth (WND); City of Westminster (WST).
} 


\section{[ Figure Three about here]}

\section{Ranking distributions and convergence clubs}

The line graphs presented in Figure One and Two provide a degree of information on the evolution of house prices across boroughs. However, further information on this and the relativities between boroughs is available via consideration of the ranking distribution of house prices. In addition, given the current focus on convergence, it is not just the levels of house prices that are informative, but also their changes. Table One provides summary information on the rankings of boroughs according to $p$ and $\Delta p .{ }^{9}$ Inspection of these figures shows that Kensington and Chelsea and City of Westminster are consistently ranked first and second in terms of house prices, with their mean ranks for $p$ being 32 and 31 respectively. In contrast, the mean ranking of 1.05 for $p$ for Barking and Dagenham reflects that this borough had the lowest level of house prices in all but one of the 22 years considered. The mean rankings for $\Delta p$ show a similar, although reduced, consistency across boroughs. Again, the results for $\Delta p$ illustrate a number of apparent regularities in the distributions. For example, while Kensington and Chelsea, City of Westminster and Barking and Dagenham return the two highest and the lowest mean ranks for $\Delta p$, the dispersion of mean ranks across boroughs for $\Delta p$ is reduced relative to that for $p$. To explore the apparent regularities in the positioning of boroughs with regard to $p$ and $\Delta p$ in a more formal manner, the Friedman (1937) ranks test $\left(Q_{F}\right)$ can be employed to test the null hypothesis of equal population means across boroughs:

\footnotetext{
9 Rankings are generated in ascending order across the 32 boroughs. Hence rankings from 1 (the lowest level) to 32 (the highest) are generated for every period in the sample.
} 
(2) $\quad Q_{F}=\frac{12}{m k(k+1)} \sum_{j=1}^{k} R_{j}^{2}-3 m(k+1)$

where $\left\{R_{j}, m, k\right\}$ denote the sum of the per period ranking of borough $j$ over the sample, the time periods considered (22 years) and the cross-sectional dimension (32 boroughs) respectively. Application of the test to using ranking for $p$ and $\Delta p$ results in $Q_{F}=614.12$ ( $p$ $=0.00 \%)$, and $Q_{F}=98.73(p=0.00 \%)$ respectively. Clearly the overwhelming rejections of the null indicate a clear difference in house prices and their changes across boroughs.

\section{[ Table One about here ]}

While the Friedman test results indicate marked differences the ranking of boroughs with regard to in $p$ and $\Delta p$, this analysis is based upon consideration of all 32 boroughs and it may be commonalities in price adjustment exist between subsets of the boroughs. As an initial means of exploring this, Figures Four and Five report Box-Whisker graphs of the ranking distributions of boroughs for $p$ and $\Delta p$. While an informal means of analysis, Figure Four does suggest some groupings of boroughs with regard to house prices with a small collection of boroughs moving around in the top end of the ranking distribution, with two larger groupings existing in the middle (Barnet, Brent, Ealing, Haringey...) and lower end (Bexley, Bromley, Croydon, Enfield, Greenwich...) of the ranking distribution. The results for price changes presented in Figure Five show increased similarities between boroughs with multiple occurrences of overlapping ranking ranges across boroughs.

\section{[ Figures Four and Five about here ]}

In combination, Figures Four and Five indicate a degree of commonality with regard to movements in $p$ and $\Delta p$ which the average rankings and results from application of the Friedman test do not capture. To examine this issue, the Nemenyi (1963) test can be employed. While the Friedman test can be viewed as testing equal population means in multiple series, 
the Nemenyi test provides an analogous form of analysis in a pairwise context via comparison of the difference between mean ranks for the two boroughs under examination with the critical difference $Q_{N}$ :

$$
Q_{N}=\frac{q_{\alpha}}{\sqrt{2}} \sqrt{\frac{k(k+1)}{6 m}}
$$

where $q_{\alpha}$ denotes the studentized range distribution. ${ }^{10}$ Given the current focus on convergence, the occasions in which pairings of boroughs reject the null for both $p$ and $\Delta p$ at the 5\% level under application of the Nemenyi test are noted. In such instances, the Nemenyi test indicates that the two boroughs under examination differ with regard to both the level of prices and their changes. These summarised results from application of the Nemenyi test are reported in Table Two. This table provides information for each borough concerning the number of other boroughs where it is found to differ in terms of $p$ and $\Delta p$ and whether this is as a result of these boroughs being lower or higher in the ranking distributions. The more extreme cases presented in Table Two reflect the findings noted when considering the mean ranks of the boroughs with, for example, the City of Westminster having statistically different rankings with regard to prices and changes in prices in comparison to 16 boroughs occupying lower positions in the ranking distributions. Conversely, Barking and Dagenham is found to differ significantly from 10 other boroughs in terms of $p$ and $\Delta p$ as a result of these other boroughs being higher in the ranking distributions. However, beyond these two extreme boroughs, and the similarly extreme results for Kensington and Chelsea for which the null is rejected for prices and changes in prices against 13 lower ranked boroughs, this analysis reveals a number of more subtle differences between rankings. To exploit this information, the

\footnotetext{
${ }^{10}$ The complexities of the test are not reported here but details, along with the PMCMRplus R-based software package employed to generate the results, are available from https://CRAN.R-project.org/package=PMCMR.
} 
boroughs other than the three extreme cases of Kensington and Chelsea, City of Westminster and Barking and Dagenham are grouped into three tiers. The middle tier contains those boroughs for which joint rejection under the Nemenyi test is not observed, with the upper and lower tiers containing those boroughs for which rejection is observed as a result of the presence of other lower and higher ranked boroughs respectively.

\section{[ Table Two about here ]}

The results provided in Table Two lead to the three-tier collection of convergence clubs below:

Top Tier: $\quad$ Camden, Hackney, Hammersmith \& Fulham, Islington, Lambeth, Richmond upon Thames, Southwark, Wandsworth.

Middle Tier: $\quad$ Barnet, Brent, Ealing, Haringey, Kingston upon Thames, Tower Hamlets.

Lowest Tier: Bexley, Bromley, Croydon, Enfield, Greenwich, Harrow, Havering, Hillingdon, Hounslow, Lewisham, Merton, Newham, Redbridge, Sutton, Waltham Forest.

To examine whether these potential convergence clubs do actually exhibit convergence, $\sigma$ convergence is examined for the proposed groupings, with the results presented in Figure Six. Despite some movement in the plotted coefficients of variation through time, convergence is apparent for all three clubs, with the initial value of 100 dropping for all groupings with decreases of $39.2 \%, 82.9 \%$ and $26.5 \%$ respectively noted at the end of the sample. While all groups exhibit convergence, it is clearly the middle tier that displays the greatest degree of convergence with boroughs in this club experiencing substantial narrowing in the distribution of their prices.

\section{[ Figure Six about here ]}




\section{Considering convergence results}

The above analysis has lead to the detection of a three-tier system displaying clear convergence in house prices. While this has been a primarily empirical exercise designed to exploit information in borough-level house price data for the purpose of assessing submarket convergence, potential factors underlying the existence of the identified clubs can be considered.

Before discussing various theoretical proposals concerning the evolution of borough-level house prices, Figure Seven is presented to provide a visual representation of the three-tier system. ${ }^{11}$ Two issues are immediately apparent from inspection of this figure. First, there is a clear Inner/Outer London dimension to the results which arises with the Top Tier convergence club being dominated by Inner London boroughs while the Lowest Tier is dominated by Outer London boroughs. However, the use of 'dominated' is important as these tiers are not exclusively populated by either Inner or Outer boroughs, with the Richmond upon Thames (Outer London) appearing in the Top Tier, while Lewisham and Greenwich (both Inner London) occupy positions in the Lowest Tier. The second feature illustrated by Figure Seven is the contiguous nature of boroughs within the specified groupings. While the Top Tier grouping is clustered around the elite pairing of Kensington and Chelsea and the City of Westminster, the Lowest Tier is spread around the outside of Greater London. The Middle Tier is predominantly a grouping to the north west of central London with the exceptions of

\footnotetext{
11 This graph was created using the mapping template available from the London Datastore and can be accessed via: https://data.london.gov.uk/dataset/excel-mapping-template-for-london-boroughs-and-wards.
} 
Kingston upon Thames and Tower Hamlets to the south west and east respectively. However, in all cases the Middle Tier boroughs border upon Top Tier boroughs.

Considering the geographical issues raised above, the displacement demand effect proposed by Hamnett (2009a) in relation to East London boroughs receives mixed support from the ranking distributions and the identified convergence clubs. While Hackney and Tower Hamlets have experienced rapid house price increases, Barking and Dagenham has seen its median price move from $£ 29,691$ below the average across the 31 other boroughs at the start of the sample to $£ 208,158$ below this average by the end of the sample. Similarly, evidence of a displaced demand effect influencing other East London boroughs is not apparent. Indeed, it could be argued that where evidence of displaced demand from the centre does occur, it takes the form of a north-westerly movement illustrated by the identified Middle Tier. An issue to consider here is that where references have been in previous research to higher percentage growth rates in lower priced areas, this obviously does not ensure actual convergence. As a simple example, a $10 \%$ growth rate in a lower priced Area A and 5\% growth rate in a higher price Area B will actually lead to a widening of the price gap if the initial prices were $£ 100,000$ and $£ 300,000$ respectively as the gap will increase from $£ 200,000$ to $£ 205,000$. Higher growth rates for some boroughs have been discussed previously in the literature, but clearly that cannot be taken to automatically imply convergence in the sense of closing the actual gap between prices. ${ }^{12}$

With regard to the proposed effects of gentrification and right-to-buy policies, these are reflected in the detected convergence clubs with, for example, the 'super-gentrified' Islington (Butler and Lees, 2006) and the boroughs typically considered to exemplify right-to-buy (Wandsworth and the City of Westminster) appearing in the Top Tier or elite grouping. Beyond

\footnotetext{
12 The difficulty in measuring convergence is further illustrated by this example as while the actual gap between prices widens, the ratio of high to low prices closes, falling from 3 to 2.9. We are grateful to a referee for noting this point.
} 
the identified linkages to an Inner/Outer London geographical factor, displaced demand, gentrification and right-to-buy policies, alternative factors can be considered in relation to the convergence clusterings identified. While Gibbons (2004) has examined the relationship between crime and house prices, its impact is difficult to evaluate in the present circumstances with, for example, the City of Westminster being the leading borough for crime yet in an elite pairing with regard to house prices, and 'leafy' lower priced boroughs such as Bromley, Havering, Merton and Sutton typically very low in the distribution of crime. However, this reflects the myriad of factors impacting upon house prices and their varying effects and relevance across different boroughs. This issue is further illustrated by travel considerations. For example, while a premium is attached to Tube station access, a borough without a single station can appear in a higher Tier than one with numerous stations (e.g. Kingston upon Thames and Newham). Turning to the more recently researched issue of the impact of foreign investment and immigration on London house prices as considered in Badarina and Ramadorai (2018), there are links of a more direct nature to be established. First, the influx of foreign investment closely corresponds to the identified convergence clubs with its association with the elite pairing of Kensington and Chelsea and the City of Westminster within the London market. Second, a link with immigration is apparent also via the close correspondence between the high levels of immigration in areas associated with the Middle Tier of convergence clubs identified to the north-west of central London.

\section{[ Figure Seven about here ]}

\section{Concluding remarks}


The above analysis has extended recent research into price adjustment within the London housing market via the application of a novel method combining the analysis of ranking distributions and convergence techniques. The results obtained add to previous studies by detecting submarket groupings of boroughs which exhibit substantial convergence. This contrasts with the findings of previous research which did not seek to establish such convergence clubs and presented limited evidence of convergence across the London market as a whole. With regard to the robustness of the findings obtained, it can be noted that similar results were obtained from an examination of mean, rather than median, house prices. ${ }^{13}$

While the identified convergence clubs do not match the 'Leafy Retreat', 'Pleasant Crescent' etc. groupings of ADV and GLAEconomics (2004), they can be related to various factors concerning displaced demand, gentrification, housing policy, immigration and foreign investment. However, the nature of the impact of these factors is complex and will often impact to different degrees on house price adjustment within a single borough. Consequently, the examination of the exact influence of underlying factors is the subject of future research following the establishment of convergence clusterings and their associated commonalities.

13 This analysis was undertaken in an earlier version of the paper. 


\section{References}

Abbott A. and De Vita, G. (2012). Pairwise convergence of district-level house prices in London. Urban Studies 49, 719-738.

Alexander, C. and Barrow, M. (1994). Seasonality and cointegration of regional house prices in the UK. Urban Studies 31, 1667-1689.

Ashworth, J. and Parker, S. (1997). Modelling regional house prices in the UK. Scottish Journal of Political Economy 44, 225-246.

Badarina, C. and Ramadorai, T. (2018). Home away from home? Foreign demand and London house prices. Journal of Financial Economics 130, 532-555.

Barro, R. (1991) Economic growth in a cross section of countries, Quarterly Journal of Economics 106, 407-443.

Baumol, W. (1986). Productivity growth, convergence and welfare: What the long-run show. American Economic Review 76, 1072-1085.

Brueckner J. (1997). Consumption and investment motives and the portfolio choices of homeowners. Journal of Real Estate Finance and Economics 15, 159-180.

Bayer, P., Ellickson, B. and Ellickson, P. (2010). Dynamic asset pricing in a system of local housing markets. American Economic Review 100, 368-372.

Butler, T. and Lees, L. (2006). Super-gentrification in Barnsbury, London: globalization and gentrifying global elites at the neighbourhood level, Transactions of the Institute of British Geographers NS, 31.

Case, K., Quigley, J. and Shiller, R. (2013). Wealth effects revisited 1975-2012. Critical Finance Review 2, 101-128.

Chang, A. and Li, P. (2017). A pre-analysis plan to replicate sixty Economics research papers that worked half of the time. American Economic Review 107, 60-64.

Clemens, M. (2017). The meaning of failed replications: A review and proposal. Journal of Economic Surveys 31, 326-342. 
Cook, S. (2003). The convergence of regional house prices in the UK. Urban Studies 40, 22852294.

Cook, S. (2005a). Regional house price behaviour in the UK: Application of a joint testing procedure. Physica A 345, 611-621.

Cook, S. (2005b). Detecting long-run relationships in regional house prices in the UK. International Review of Applied Economics 19, 107-118.

Cook, S. (2006). A non-parametric examination of asymmetrical behaviour in the UK housing market. Urban Studies 47, 2067-2074.

Cook, S. (2012). $\beta$-convergence and the cyclical dynamics of UK regional house prices. Urban Studies 49, 203-218.

Cook, S. and Watson, D. (2015). A new perspective on the ripple effect in the UK housing market: Comovement, cyclical subsamples and alternative indices. Urban Studies 14, 30483062 .

Cook, S. and Watson, D. (2017). Mean and variance equation dynamics: Time deformation, GARCH and a robust analysis of the London housing market. International Journal of Finance and Economics 22, 304-318.

Costello, G., Fraser, P. and Groenewold, N. (2011). House prices, non-fundamental components and interstate spillovers: The Australian experience, Journal of Banking and Finance 35, 653-669.

Drake, L. (1995). Testing for convergence between UK regional house prices. Regional Studies 29, 357-366.

Friedman, M. (1937). The use of ranks to avoid the assumption of normality implicit in the analysis of variance. Journal of the American Statistical Association 32, 675-701.

Frank, M. and Saxe, R. (2012). Teaching replication. Perspectives on Psychological Science 7, 600-604.

Friedman, M. (1992). Do old fallacies ever die? Journal of Economics Literature 30, 21292132. 
Gallin, J. (2006). The long-run relationship between house prices and income: Evidence from local housing markets. Real Estate Economics 34, 417-438.

GLAEconomics (2004) London's Housing Submarkets, Greater London Authority. https://www.london.gov.uk/sites/default/...housing_submarkets_report_for_web.pdf

Gibbons, S. (2004). The costs of urban property crime. Economic Journal 114, F441-F463.

Goodhart, C. and Hoffman, B. (2007). House Prices and the Macroeconomy: Implications for Banking and Price Stability, Oxford: Oxford University Press.

Goetzmann, W. (1993). The single family home in the investment portfolio. Journal Real Estate Finance and Economics 6, 201-222.

Guissani, B. and Hadjimatheou, G. (1991). Modelling regional house prices in the United Kingdom. Papers in Regional Science 70, 201-219.

Hamnett, C. (2009a). Spatially displaced demand and the changing geography of house prices in London, 1995-2006. Housing Studies 24, 301-320.

Hamnett, C. (2009b). The new Mikado? Tom Slater, gentrification and displacement, City 13, 476-482.

Han, L. (2013). Understanding the puzzling risk-return relationship for housing. Review of Financial Studies 26, 877-928.

Hendry, D. (1984). Econometric modelling of house prices in the United Kingdom, in Hendry, D. and Wallis, K. (eds.). Econometrics and Quantitative Economics, Oxford: Blackwells.

Hoffler, J. (2017). Replication and economics journal policies. American Economic Review $107,52-55$.

Holly S. and Jones, N. (1997). House prices since the 1940s: cointegration, demography and asymmetries. Economic Modelling 14, 549-565.

Holmans, A. (1990). House price changes through time at national and sub-national level, Government Economic Service Working Paper 110. 
Holmes, M. (2007). How convergent are regional house prices in the United Kingdom? Some new evidence from panel data unit root testing. Journal of Economic and Social Research 9, 117.

Holmes, M. and Grimes, A. (2008). Is there long-run convergence among regional house prices in the UK? Urban Studies 45, 1531-1544.

Holmes, M., Otero, J. and Panagiotidis, T. (2018). Climbing the property ladder: An analysis of market integration in London property prices. Urban Studies 55, 2660-2681.

Hudson, C., Hudson, J. and Morley, B. (2018). Differing house price linkages across UK regions: A multi-dimensional recursive ripple model. Urban Studies 55, 1636-1654.

Le, M. and Liu, C. (2013). Ripple effects of house prices: considering spatial correlations in geography and demography. International Journal of Housing Markets and Analysis 6, 284299.

Lean, H. and Smyth, R. (2013). Regional house prices and the ripple effect in Malaysia. Urban Studies 50, 895-922.

Lee, C. and Chien, M. (2011). Empirical modelling of regional house prices and the ripple effect. Urban Studies 48, 2029-2047.

MacDonald, R. and Taylor, M. (1993). Regional house prices in Britain: Long-run relationships and short-run dynamics. Scottish Journal of Political Economy 40, 43-55.

Makel, M. and Plucker, J. (2014). Facts are more important than novelty: Replication in the education sciences. Educational Researcher 43, 304-316.

McNeeley, S. and Warner, J. (2015). Replication in criminology: A necessary practice. European Journal of Criminology 12, 581-597.

Meen, G. (1999). Regional house prices and the ripple effect: A new interpretation. Housing Studies $14,733-753$.

Meen, G. and Andrew, M. (1998). Modelling Regional House Prices: A Review of the Literature, Report to the Department of Environment, Transport and the Regions.

Nellis, J. and Longbottom, A. (1981). An empirical analysis of the determination of house prices in the United Kingdom. Urban Studies 18, 9-22. 
Nemenyi, P. (1963). Distribution-free Multiple Comparisons. PhD thesis, Princeton University.

Nygaard, C. and Meen, G. (2016). The distribution of London residential property prices and the role of spatial lock-in. Urban Studies 50, 2535-2552.

Open Science Collaboration (2015). Estimating the reproducibility of psychological science. Science 349.

Pesaran, M. (2007). A pair-wise approach to testing for output and growth convergence. Journal of Econometrics 138, 312-355.

Peterson, W., Holly, S. and Gaudoin, P. (2002). Further Work on an Economic Model of the Demand for Social Housing. Report to the Department of the Environment, Transport and Regions.

Phillips P. and Sul D. (2007). Transition modeling and econometric convergence tests. Econometrica 75, 1771-1855.

Quah, D. (1993). Galton's fallacy and the convergence hypothesis. Scandinavian Journal of Economics 95, 427-443.

Shiller, R. and Perron, P. (1985). Testing the random walk hypothesis: power versus frequency of observations. Economics Letters 18, 381-386.

Slater, T. (2009). Missing Marcuse: On gentrification and displacement, City 13, 292-311.

Sukhtankar, S. (2017). Replications in Development Economics. American Economic Review $107,32-36$

Winfree, J. (2010). Issues with replicating results in sports Economics. Journal of Sports Economics 11, 48-59.

Zhang, L., Hui, E. and Wen, H. (2017). The regional house prices in China: Ripple effect or differentiation. Habitat International 67, 118-128. 
Table One: Mean Rankings for House Prices and Changes in House Prices

\begin{tabular}{|c|c|c|}
\hline Borough & House Prices & Changes in House Prices \\
\hline Kensington \& Chelsea & 32.00 & 25.33 \\
\hline Westminster & 31.00 & 27.38 \\
\hline Camden & 29.73 & 22.52 \\
\hline Hammersmith \& Fulham & 29.18 & 23.81 \\
\hline Richmond upon Thames & 27.77 & 20.57 \\
\hline Islington & 26.77 & 21.90 \\
\hline Wandsworth & 26.36 & 22.86 \\
\hline Barnet & 23.95 & 15.86 \\
\hline Kingston upon Thames & 21.50 & 15.48 \\
\hline Tower Hamlets & 21.36 & 17.19 \\
\hline Southwark & 21.00 & 19.52 \\
\hline Harrow & 19.82 & 15.24 \\
\hline Lambeth & 19.73 & 18.90 \\
\hline Ealing & 19.05 & 16.90 \\
\hline Brent & 17.86 & 16.33 \\
\hline Merton & 16.95 & 15.38 \\
\hline Hackney & 16.86 & 19.29 \\
\hline Bromley & 15.95 & 13.62 \\
\hline Haringey & 15.64 & 17.43 \\
\hline Hounslow & 13.05 & 12.81 \\
\hline Redbridge & 11.68 & 13.71 \\
\hline Hillingdon & 11.59 & 12.43 \\
\hline Enfield & 8.68 & 11.76 \\
\hline Sutton & 8.09 & 10.24 \\
\hline Greenwich & 7.23 & 12.52 \\
\hline Waltham Forest & 6.82 & 14.67 \\
\hline Lewisham & 5.82 & 12.95 \\
\hline Havering & 5.45 & 9.29 \\
\hline Croydon & 5.05 & 11.29 \\
\hline Newham & 4.05 & 13.43 \\
\hline Bexley & 3.14 & 9.05 \\
\hline Barking \& Dagenham & 1.05 & 7.86 \\
\hline
\end{tabular}

Notes: The above figures represent average rankings across the full sample for the house prices and changes in house prices. 
Table Two: Joint rejections under the Nemenyi Test

Borough House Prices

Barking \& Dagenham (10H)

Barnet (0)

Bexley $(7 \mathrm{H})$

Brent (0)

Bromley (2H)

Camden (4L)

Croydon (5H)

Ealing (0)

Enfield $(3 \mathrm{H})$

Greenwich $(3 \mathrm{H})$

Hackney (1L)

Hammersmith \& Fulham (8L)

Haringey (0)

Harrow $(1 \mathrm{H})$

Havering $(7 \mathrm{H})$

Hillingdon $(3 \mathrm{H})$

Hounslow $(2 \mathrm{H})$
Camden, Hackney, Hammersmith \& Fulham, Islington, Kensington \& Chelsea, Lambeth, Richmond upon Thames, Southwark, Wandsworth, City of Westminster.

None.

Camden, Hammersmith \& Fulham, Islington, Kensington \& Chelsea, Richmond upon Thames, Wandsworth, City of Westminster.

None

Kensington and Chelsea, City of Westminster.

Barking \& Dagenham, Bexley, Havering, Sutton.

Camden, Hammersmith \& Fulham, Kensington \& Chelsea, Wandsworth, City of Westminster.

None

Hammersmith \& Fulham, Kensington \& Chelsea, City of Westminster.

Hammersmith \& Fulham, Kensington \& Chelsea, City of Westminster.

Barking \& Dagenham.

Barking \& Dagenham, Bexley, Croydon, Enfield, Greenwich, Havering, Hillingdon, Sutton.

None.

City of Westminster

Camden, Hammersmith \& Fulham, Islington, Kensington \& Chelsea, Lambeth, Wandsworth, City of Westminster.

Hammersmith \& Fulham, Kensington \& Chelsea, City of Westminster.

Kensington \& Chelsea, City of Westminster. 
Table Two (continued): Joint rejections under the Nemenyi Test

Borough House Prices

\section{Islington (4L)}

Kensington \& Chelsea (13L)

Kingston upon Thames (0)

Lambeth (1L)

Lewisham $(2 \mathrm{H})$

Merton (1H)

Newham $(2 \mathrm{H})$

Redbridge $(2 \mathrm{H})$

Richmond upon Thames (3L)

Southwark (1L)

Sutton $(6 \mathrm{H})$

Tower Hamlets (0)

Waltham Forest $(1 \mathrm{H})$

Wandsworth (5L)

City of Westminster (16L)
Barking \& Dagenham, Bexley, Havering, Sutton.

Barking \& Dagenham, Bexley, Bromley, Croydon, Enfield, Greenwich, Harrow, Havering, Hillingdon, Hounslow, Lewisham, Newham, Redbridge, Sutton.

None

Bexley.

Kensington \& Chelsea, City of Westminster.

Westminster.

Kensington \& Chelsea, City of Westminster.

Kensington \& Chelsea, City of Westminster.

Barking \& Dagenham, Bexley, Havering.

Barking \& Dagenham.

Camden, Hammersmith \& Fulham, Islington, Kensington \& Chelsea, Wandsworth, City of Westminster.

None

City of Westminster.

Barking \& Dagenham, Bexley, Croydon, Havering, Sutton.

Barking \& Dagenham, Bexley, Bromley, Croydon, Enfield, Greenwich, Harrow, Havering, Hillingdon, Hounslow, Lewisham, Merton, Newham, Redbridge, Sutton, Waltham Forest.

Notes: The figures in parentheses denote the number of boroughs for which the Nemenyi test rejects the null for both house prices and their changes, with L/H denoting whether these boroughs are lower/higher in the ranking distribution. For example, 'City of Westminster (16L)' denotes that the null of equal population means of both prices and changes in prices is rejected for Westminster in comparison with 16 boroughs which have lower rankings. 


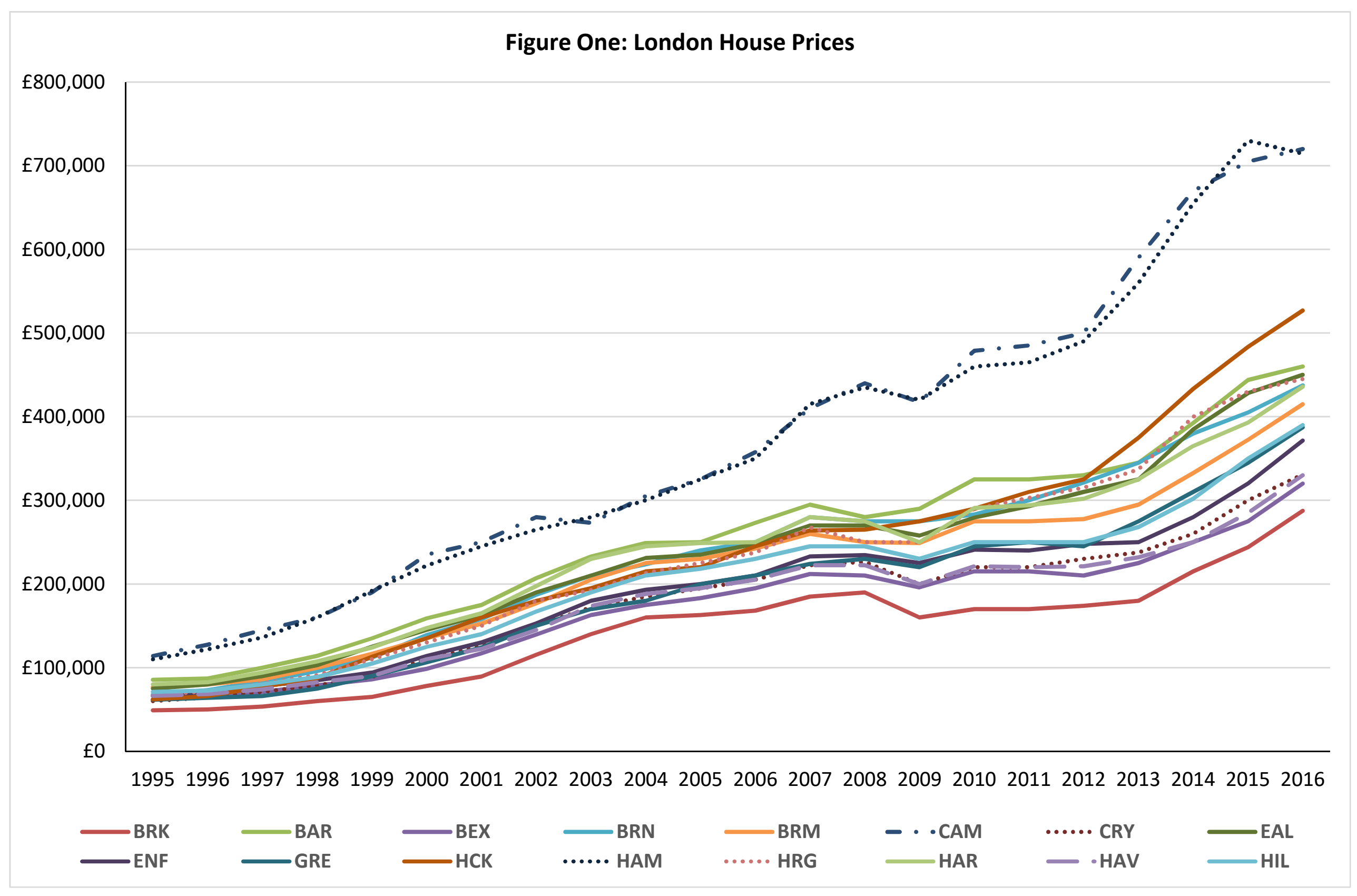




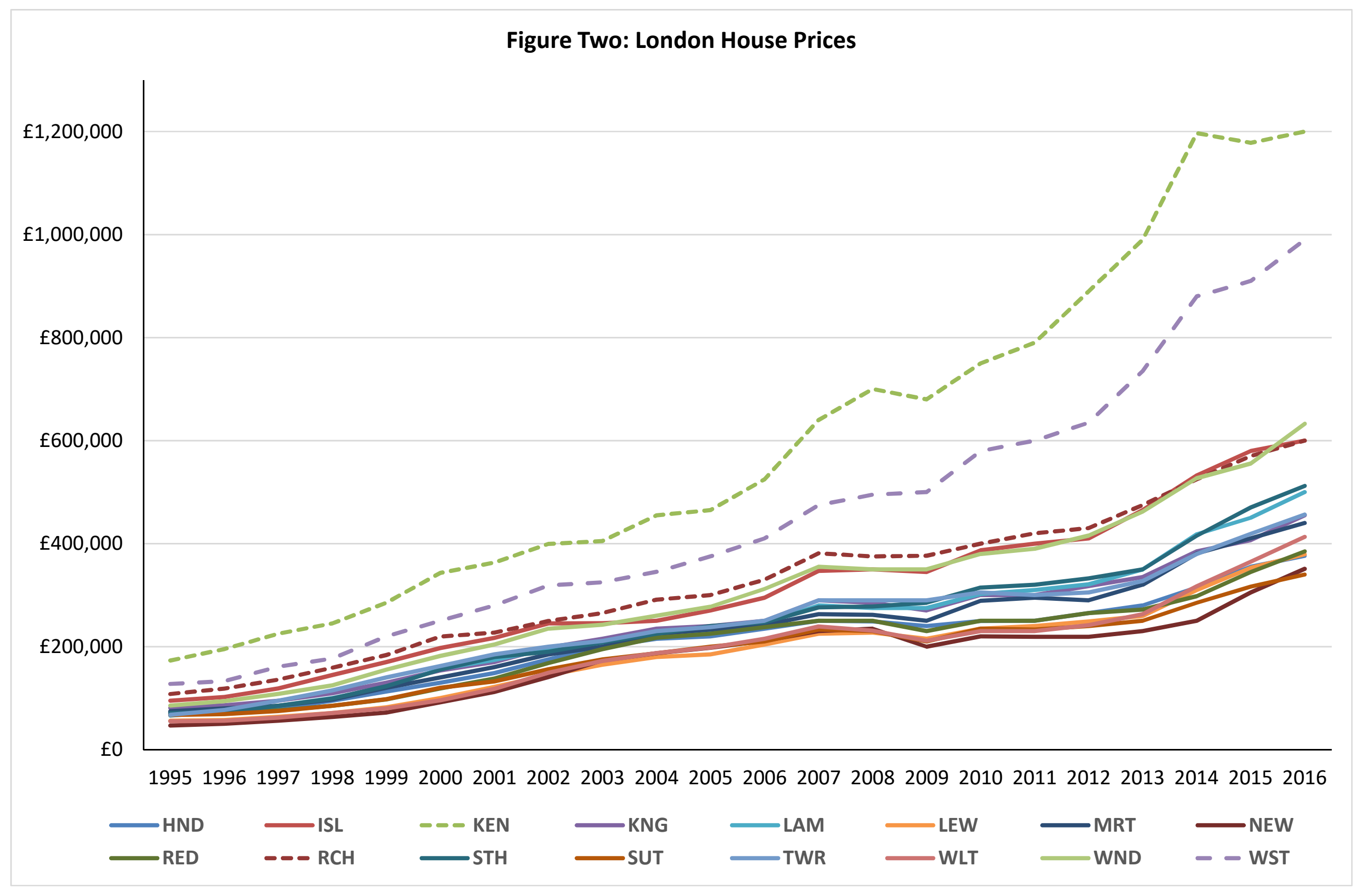




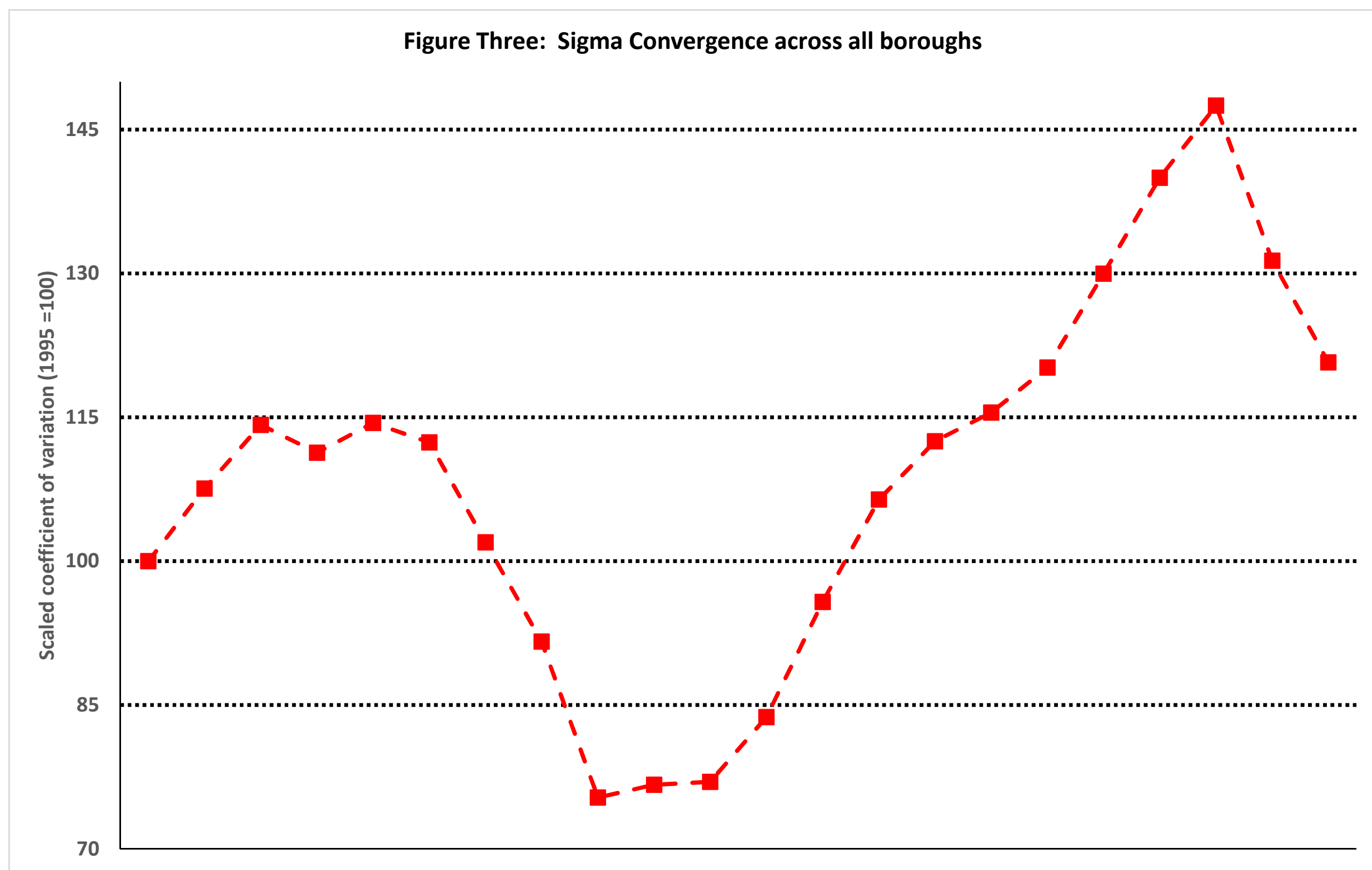

1995199619971998199920002001200220032004200520062007200820092010201120122013201420152016 
Figure Four: Distribution of rankings of house prices across boroughs

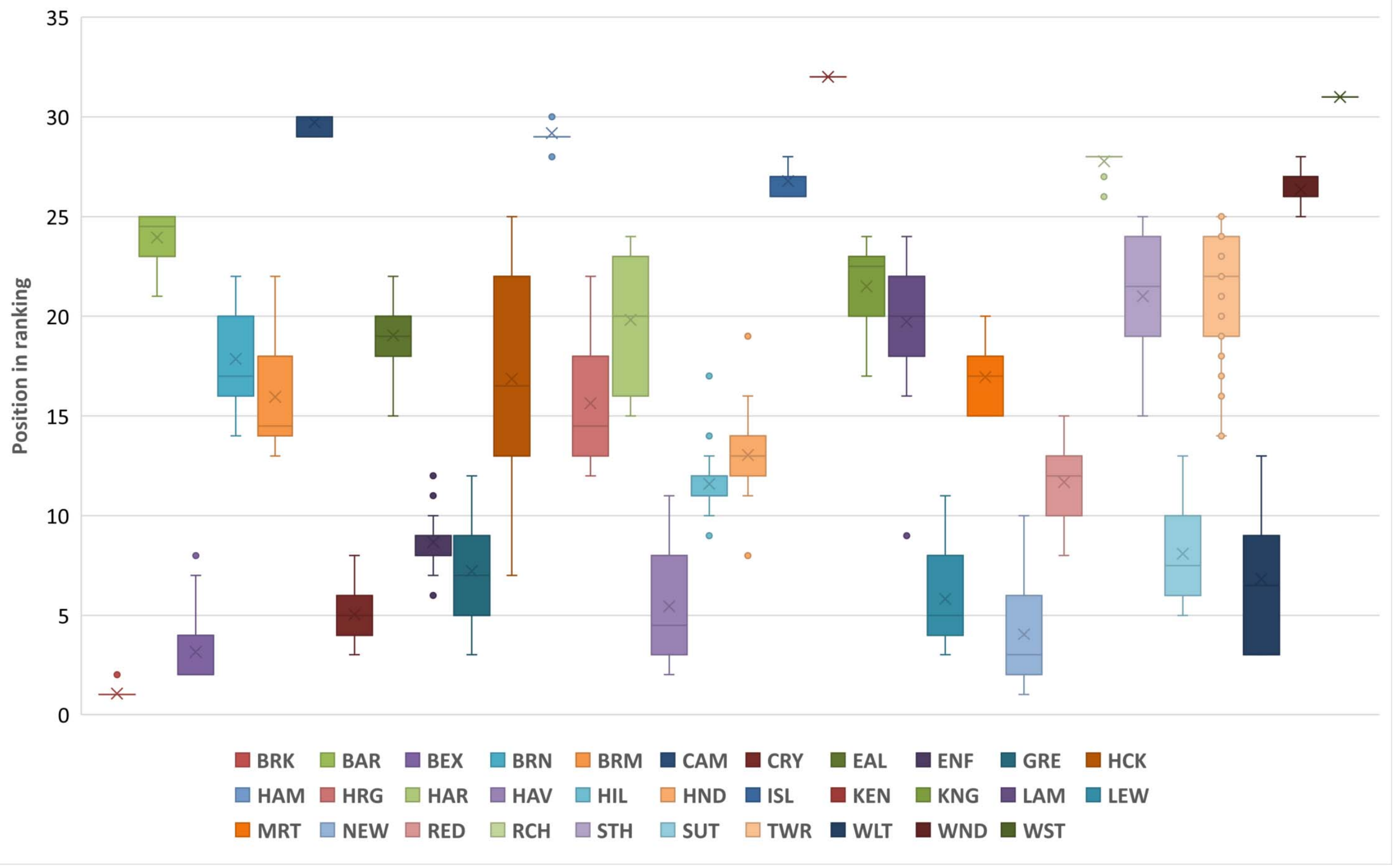


Figure Five: Distribution of rankings of house price changes across boroughs

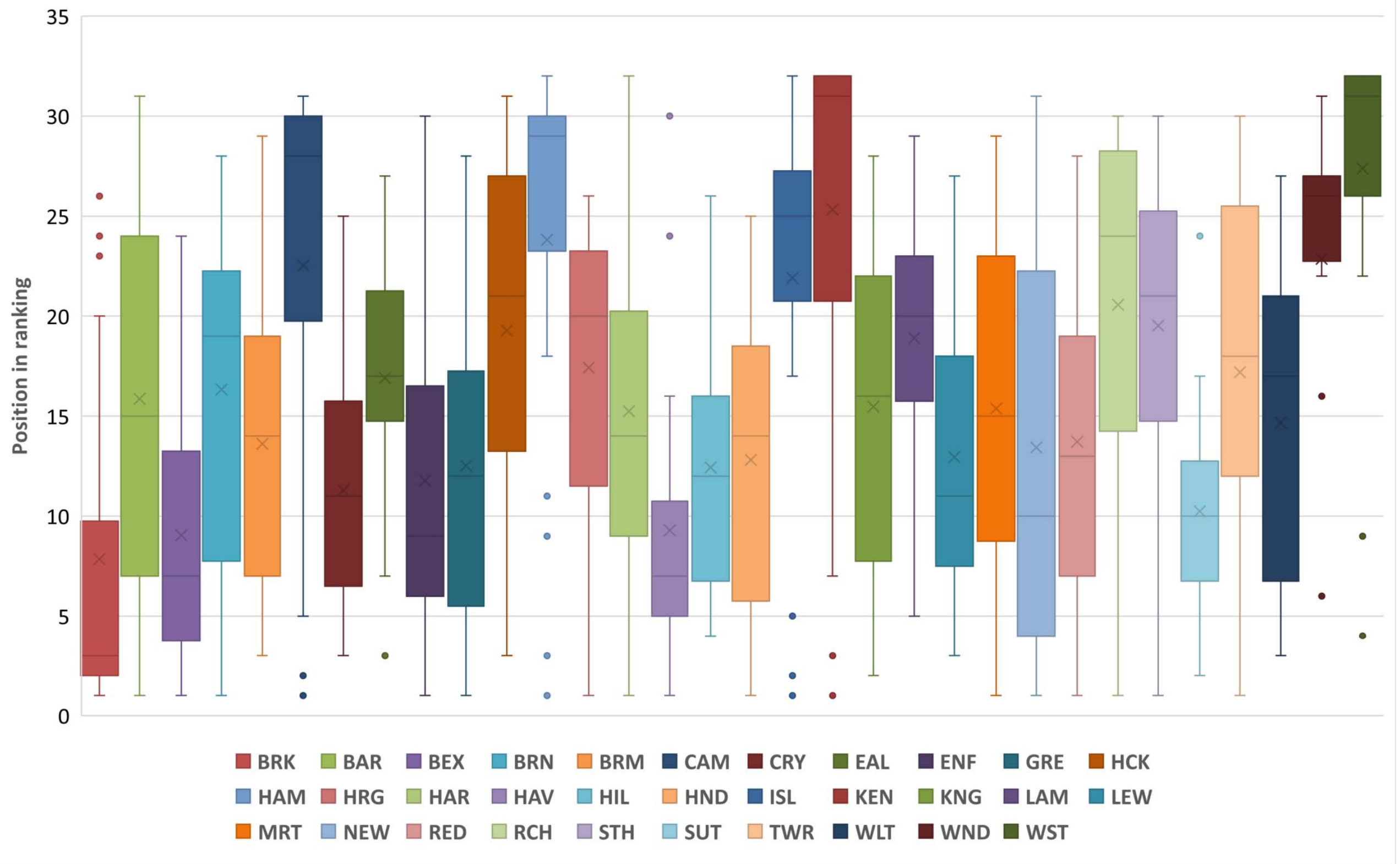




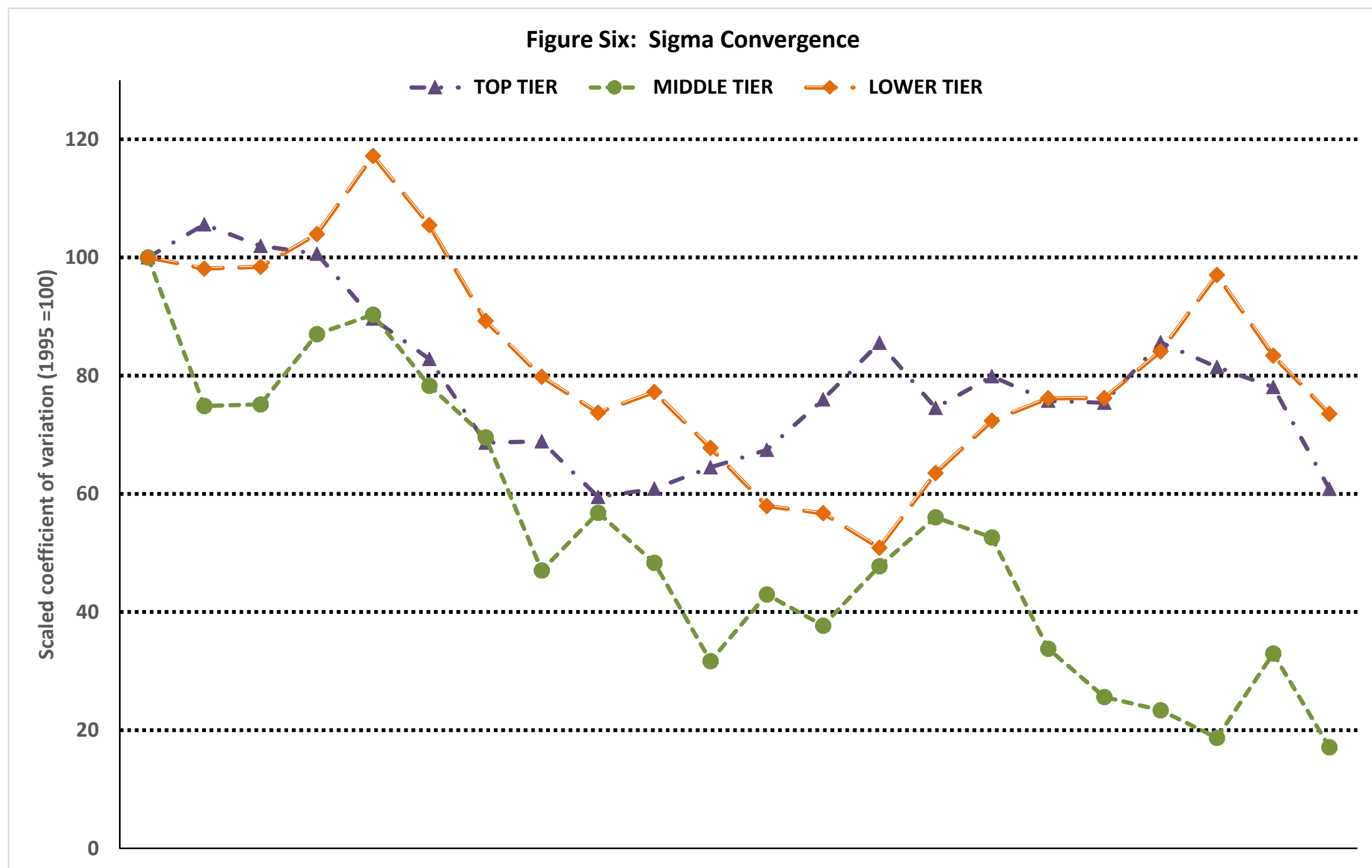

1995199619971998199920002001200220032004200520062007200820092010201120122013201420152016 


\section{Figure Seven: London Convergence Clubs}

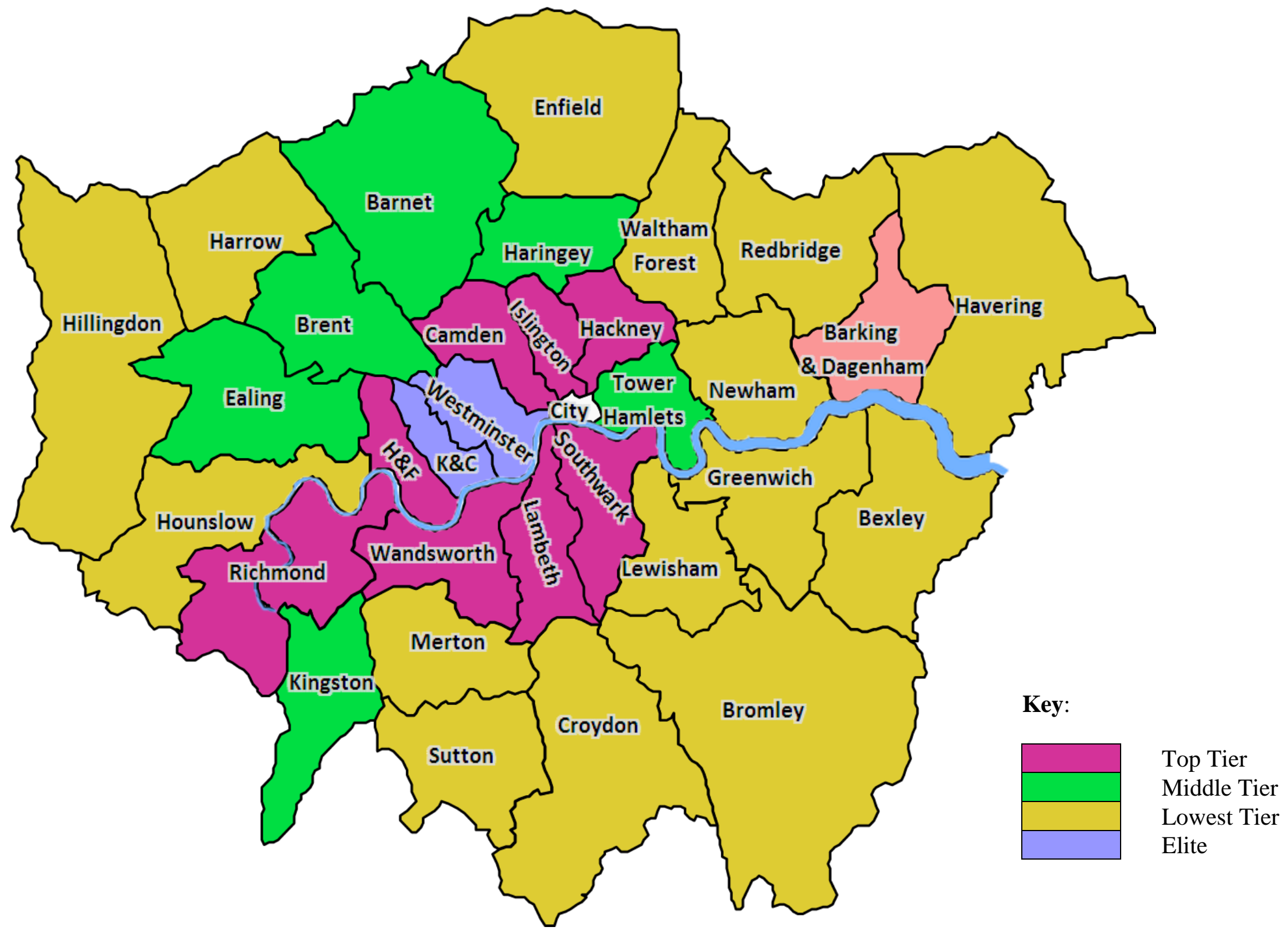

